\title{
A INCLUSÃO DO DEFICIENTE NA SOCIEDADE EDUCACIONAL: UMA ANÁLISE DO VIÉS PRINCIPIOLÓGICO DA EFICÁCIA HORIZONTAL DOS DIREITOS FUNDAMENTAIS APLICADA À RELAÇÃO DOS PARTICULARES DA EDUCAÇÃO ${ }^{1}$
}

THE INCLUSION OF THE DISABLED IN THE EDUCATIONAL SOCIETY: AN ANALYSIS OF THE PRINCIPIOLOGICAL BIAS OF THE HORIZONTAL EFFECTIVENESS OF FUNDAMENTAL RIGHTS APPLIED TO THE RELATIONSHIP OF EDUCATIONAL PARTICULARS

Larissa Janoni de ARAUJO

Roberta dos Santos Pereira de CARVALHO ${ }^{3}$

ISSUE DOI: $10.21207 / 2675-0104.2018 .724$

\section{RESUMO}

O objetivo principal do presente artigo empreendeu investigar os obstáculos de outrora e os ainda não sobrelevados pela Instituição de Ensino Regular Privada, no que diz respeito a inclusão da pessoa com deficiência no ambiente escolar privado, e, se essa mesma inclusão dentro do vínculo relacional

\footnotetext{
${ }^{1} \mathrm{O}$ presente artigo sintetiza a monografia de conclusão da pesquisa, realizada para o Programa Interno de Bolsas de Iniciação Científica (PIBIC 2017-2018) da Faculdade de Direito de Franca (FDF), Franca/SP.

${ }^{2}$ Discente da Faculdade de Direito de Franca (FDF), Franca/SP. Bolsista do Programa Interno de Bolsas de Iniciação Científica (PIBIC 2017-2018).

${ }^{3}$ Possui graduação em Direito pela Universidade Estadual Paulista Júlio de Mesquita Filho (1993) e mestrado em Direito das Relações Econômico Empresariais pela Universidade de Franca (2003). Atuou como professor titular da Universidade de Franca - UNIFRAN, até junho de 2008. Atualmente execer a docencia junto ao Centro Univesitário da Fundação Educacional Guaxupé-MG e na Faculdade Dr. Francsico Maeda- FAFRAM, em Ituverava-SP.
} 
particular tem sido amparada pela aplicação eficaz horizontal da norma pelos particulares da educação. Pautado em um estudo de caráter histórico sociológico, filosófico normativo e pedagógico, constata-se que a inclusão dessas pessoas depende, acima de tudo, do empenho conjunto do Estado aliado a Sociedade Educacional para que haja a operacionalização da norma fundamental também dentro do vínculo relacional particular.

Palavras-chave: Pessoa com Deficiência. Inclusão Social. Educação Privada. Eficácia Horizontal dos Direitos Fundamentais.

\section{ABSTRACT}

The main objective of this article undertook to investigate the obstacles from before and not yet overcome by Regular Private Education Institution, in respect of the inclusion of the Disabled Person in the school environment, and, if this same inclusion within the particular relational link has been protected by effective implementation of horizontal fundamental rights by individuals of education. Based on a historical character study, sociological normative philosophical and pedagogical, it is noted that the inclusion of these people depends, above all, the joint commitment of the State combined with Educational Society, to the implementation of the Fundamental Right also within particular relational link.

Keywords: Person with a disability. Social Inclusion. Private Education. Horizontal Effectiveness of Fundamental Rights.

\section{INTRODUÇÃO}

Ao longo do tempo a pessoa com deficiência, por apresentar atributos extraordinários ${ }^{4}$, esteve aquém de estar integrada ao seio da sociedade. Condicionada a se estabelecer às margens da sociedade, restou impedida de participar de suas atividades e de se relacionar com os demais membros civis.

Condição esse, que somente começou a ser desmistificada a partir do momento em que Estado e Sociedade Educacional, em empenho conjunto, passaram a assumir o caráter de entidades constitucionalizadas e democráticas, que reconhecem na pessoa com deficiência, como em qualquer outro indivíduo humano, sujeito a que se deve reconhecer a dignidade e titularidade de direitos a serem efetuados. Não só nas relações estabelecidas entre Estado e extraordinário, mas entre esse último e os particulares da educação.

A aplicação da norma fundamental, quer de caráter público, nas relações estabelecidas entre os membros civis, é princípio norteado pela aplicação da Eficácia Horizontal dos Direitos Fundamental, ao qual deve ser invocado, pela pessoa com deficiência, de quando não há o reconhecimento, dentro dessa mesma relação pelo seu análago particular,

\footnotetext{
${ }^{4}$ Ao longo do artigo, a pessoa com deficiência é identificada por indivíduo, pessoa ou ente extraordinário, e a deficiência, por vezes reputada de atributo extraordinário ou extraordinariedade. Por sua vez, os demais indivíduos, são identificados como pessoas ou entes ordinários.
} 
de que ela é pessoa digna de ter suas prerrogativas respeitadas e operacionalizadas, tanto quanto ele próprio o é.

Quanto a investigação acerca da efetivação dos Direitos Fundamentais da pessoa com deficiência dentro da relação avençada entre ela e os particulares da educação privada, é apresentado sinteticamente uma reflexão sobre o Julgamento da ADI 5357, que visa demonstrar o posicionamento do Supremo Tribunal Federal sobre o tema, e ressaltar os obstáculos que ainda devem ser sobrelevados para a de fato inclusão escolar do aluno extraordinário.

Para essa constatação, procedeu-se a um levantamento bibliográfico centrado nos Direitos Humanos; no Direito Constitucional e no Direito Civil, acompanhado por um estudo de caráter históricosociológico, e por um diálogo interdisciplinar estabelecido entre essas matérias e a assinalada pela Pedagogia e Filosofia do Direito.

\section{O CONTEXTO DA SOCIEDADE EDUCACIONAL MARGINALIZADORA}

O reconhecimento da amplitude do valor fundamental da pessoa com deficiência por parte do Estado e da Sociedade, que conduz a compreensão da série de dispositivos normativos destinados ao amparo dessas pessoas, depende da análise do contexto histórico-sociológico em que esse mesmo indivíduo se encontrava inserido.

A pessoa com deficiência no contexto de uma sociedade discriminatória, era reconhecida como personalidade débil do grupo social, sendo também reputada por imperfeita, impura, fraca, pecadora, castigada pelo divino e que, portanto, inferior, não era digna de gozar de qualquer direito, tampouco de ser enquadrada à Instituição Social: ao qual exaltava o belo, o perfeito, o robusto, o ideal..$^{5}$

Desse modo, o indivíduo extraordinário paralisado não por suas debilidades, mas pela não aceitação do seu condicionamento pelos demais, em vista da reputação discriminatória que lhe fora imputada, por sua vez, sujeitou-se a ser gerado em um ambiente estéril: o da marginalização. E assim, seguiu privado de socializa-se dentro da própria instituição, e,

\footnotetext{
${ }^{5}$ Cf. SOUZA, Tânia Mara Pinto de. Da Tutela Dos Direitos difusos e coletivos das Pessoas com Deficiência: uma breve abordagem. In: CARVALHO, Marco Cesar (ORG.) CIA, Michele (ORG.). Apresentação de Henrique Gaberllini Carnio. Direitos Fundamentais: história, evolução e problemas atuais. 1.ed. Passos- MG: Gráfica e Editora São Paulo, 2015. p., p. 355-356.
} 
principalmente, privado de socializar-se com os demais membros que compõe a sociedade.

O papel de membro marginalizado a que lhe fora imputado, o impediu de frequentar lugares de convívio público e a participar das várias atividades, qual membro ativo participante das várias instituições da sociedade, o que, por sua vez, a impediu de se relacionar e a desenvolver com habitualidade suas aptidões de ser humano ${ }^{6}$. Por essa razão, a pessoa com deficiência seguiu impedida de frequentar o primeiro ambiente socializador, que é escola regular, e de compartilhar do mesmo ambiente com os demais alunos ordinários, em vistas da extraordinariedade que a restringia.

De quando não resta espaço para que o indivíduo extraordinário exerça suas aptidões, essência de seu caráter humano, através do desenvolvimento de suas potencialidades a partir do contato com a educação e, principalmente do contato com os demais indivíduos e alunos ordinários - proposta da implementação da inclusão na rede escolar regular -, por certo, tem-se formado no seio da sociedade e à sua margem, um indivíduo reprimidamente tímido.

Que em qualquer contexto relacional, especialmente o de âmbito privativo da educação, se consolidará qual parte hipossuficiente do vínculo que venha a ser estabelecido, pelo fato de que, por muito tempo, não lhe fora permitido estar integrado ao meio. Desse modo, havia se sujeitado a acreditar que suas extraordinariedades representavam verdadeiro impasse e restrição da invocação e operacionalização de direitos, públicos e privados nas relações particulares, ditas horizontais, estabelecidas entre extraordinários e ordinários.

Ao conformar-se com a sua posição de membro hipossuficiente da organização social, a pessoa com deficiência impulsionada pela compostura recriminadora dos indivíduos ordinários postos ao seu redor, exime-se de ser incluída nos conglomerados socializantes, em virtude da falsa percepção que lhe fora imputada, de ser um indivíduo não dotado por completo de todas as suas atribuições essenciais ao ser humano, e que portanto, indivíduo menos benemerente a participar normalmente das atividades sociais, dentre todas: a de ter o acesso pleno e inclusivo à educação.

\footnotetext{
${ }^{6}$ Aptidões essas, naturais a todo ser humano: imensurável capacidade de comunicação, locomoção, compostura e intelecção.
} 


\section{O VALOR FUNDAMENTAL DA PESSOA COM DEFICIÊNCIA}

A desmarginalização da pessoa com deficiência como parte de um processo paulatino, derivou das variadas posturas políticas adotadas pelo Estado, após a série de debates suscitados em sociedade. ${ }^{7}$ A instituição estatal que em um primeiro momento condenava ao extermínio tais entes, passou no cristianismo assumir um caráter assistencial dessas personalidades ditas enfermas. No entanto, fora somente no seguinte período que esse mesmo Estado passa a integrar o extraordinário em sociedade, adaptando-o ao ambiente institucional, a partir do aprimoramento da ciência e da tecnologia ${ }^{8}$.

A partir do momento em que esse mesmo Estado passa a assumir uma postura democrática e constitucionalista, ao mesmo tempo a sociedade passa a reconhecer também no ente extraordinário a necessidade de amparar a sua integridade pessoal. $O$ que permitiu que a pessoa com deficiência ser reconhecida como ser humano digno de direitos a serem efetuados tanto quanto os demais membros que compõe a Instituição Social. ${ }^{9}$

Em outras palavras, a institucionalização da inclusão da pessoa com deficiência esteve ligada a constitucionalização da Instituição Estatal, que assumira o papel de entidade democrática, destinada a reconhecer em todos os membros que a compõem sujeitos titulares de direitos, dignos de valor e de respeito de suas extraordinariedades. ${ }^{10}$

Nas palavras da atual Presidente do Supremo Tribunal Federal, a Ministra Cármen Lúcia, o reconhecimento de dignidade requer que essa mesma sociedade democrática assuma o seguinte papel:

\footnotetext{
7 BOLONHINI JUNIOR, Roberto. Portadores de necessidades especiais: as principais prerrogativas e a legislação brasileira. São Paulo: Arx, 2004.

${ }^{8}$ No final da Idade Moderna e o início da contemporânea, com o aprimoramento da ciência e tecnologia foi possível a fabricação de equipamentos que permitiram a pessoa com deficiência integrar-se $\mathrm{s}$ a comunidade social. Sendo alguns desses: a cadeira de rodas e as bengalas, muletas, próteses, macas, os veículos adaptados. In: TISESCU, Alessandra Devuksky da Silva; SANTOS, Jackson Passos. Apontamentos históricos sobre as fases de construção dos direitos humanos da pessoa com deficiência. Disponível em: < www.publicadireito.com.br/artigos/?cod=24f984f75f37a519>.Acesso em:19.ago.2018.p.1-11.

${ }^{9}$ Cf. Id., Ibid., p.11-14, nota 6.

10 “Art. $1^{\circ}$ A República Federativa do Brasil, formada pela união indissolúvel dos Estados e Municípios e do Distrito Federal, constitui-se em Estado Democrático de Direito e tem como fundamentos: [...] III - a dignidade da pessoa humana; [...].” In: BRASIL. Constituição (1988). Constituição da República Federativa do Brasil. In: CURIA, Luiz Roberto; CÉSPEDES, Lívia; ROCHA, Fabiana Dias da; colaboradores. Vade Mecum. São Paulo: Saraiva 2016. p.5-94.
} 


\begin{abstract}
Sendo a democracia o regime político que tem como finalidade garantir ao homem uma estrutura sociopolítica destinada a permitir-lhe realizar como ser livre, vocacionado a viver segundo as suas opções concertadas com os demais em igualdade de condições para que cumpra com o seu destino, é que a dignidade da pessoa humana emerge como superlei pré-estatal, que se põe no sistema constitucional como princípio fundamental matricial de todas as demais normas. $[\ldots]^{11}$
\end{abstract}

Uma sociedade que reconhece em seus membros serem pessoas humanas dignas em direito, certamente, é uma sociedade que propicia um ambiente favorável a desenvoltura da pessoa com deficiência, como de qualquer outro semelhante seu, extraordinário ou não, segundo as suas liberdades e vocações ${ }^{12}$, imanentes da sua qualidade ser humano virtuoso, e, que requer a sua acomodação dentro do próprio núcleo social - incluso, e não à sua margem.

A pretensão pela efetivação dos direitos compreendidos no princípio da dignidade da pessoa com deficiência, por seu turno, significa evocar a concretização sob a qual se funda a própria razão da existência de uma estrutura social: a qual sustenta a garantia não somente do mínimo de existência para cada membro, mas de sua permanência incluída ao meio.

Da qual depende, acima de tudo, do compromisso da inclusão do indivíduo com deficiência, através do empenho conjunto da sociedade aliada ao Estado. Esse último por intermédio da normatização e fiscalização da eficácia das políticas e diretrizes por ele empreendidos, e a primeira, na figura dos membros instituintes da escola regular privada, através da operacionalização eficaz dos mecanismos dissertados pelo segundo, o Estado.

Compromisso esse que deve propiciar, muito mais do que a pura e simples adequação dos próprios ambientes da instituição de maneira a sobrelevar as barreiras arquitetônicas que restringem a participação do extraordinário nas instituições de ensino, mas que permita emergir de fato uma sociedade, que de maneira harmônica e inclusiva, sobreleve as barreiras preceituais e marginalizadoras que tendem a afastar a pessoa com deficiência de restar incluída a sociedade educacional.

\footnotetext{
${ }^{11}$ ROCHA, Cármen Lúcia Antunes, ROCHA, Cármen Lúcia Antunes. O princípio da dignidade da pessoa humana e a exclusão social. Disponível em: < http://egov.ufsc.br/portal/sites/default/files/anexos/32229-38415-1-PB.pdf>. Acesso em: 19.ago.2018. p.8.

${ }^{12}$ Cf. Id. Ibid.. p.1-16, nota 9.
} 


\section{4 \\ RELAÇÃO ENTRE PARTICULARES: A APLICAÇÃO DO PRINCÍPIO DA EFICÁCIA HORIZONTAL DOS DIREITOS FUNDAMENTAIS DA PESSOA COM DEFICIÊNCIA}

Em sociedade, para que o indivíduo extraordinário se a auto afirme, em tendo sido reconhecida sua dignidade, e exerça com liberalidade o desígnio de suas aptidões, é necessário para ele, e inclusive fundamental a sua sobrevivência, a articulação de vínculos, derivados não somente do elo estabelecido com a Instituição Estatal - que deve o reconhecer e o proteger, mas derivados do elo estabelecido entre o ente e os demais membros civis.

A articulação de vínculos particulares vitais a socialização do homem, como por exemplo, a estabelecida entre o aluno com deficiência e a escola, está marcada por uma por uma série de complexidades, natural de qualquer relação estabelecida por particulares porque formada por indivíduos humanos, que por si mesmos são seres altamente complexos.

Ora, o homem que apresente qualquer extraordinariedade quer se relacione com os demais membros e instituições não pode ser concebido como ser menos complexo, ou mesmo, menos digno de ter suas prerrogativas efetuadas que o seu semelhante ordinário. Partindo do princípio que a dignidade da pessoa humana deve ser reconhecida a ambos os particulares da relação.

Pois em verdade, ao considerar que todos os indivíduos que regem a sociedade, são seres humanos iguais em integridade e em oportunidade de acesso a todos os âmbitos em sociedade, inclusive o educacional, é reconhecida na pessoa com deficiência, autonomia e virtudes suficientes para que se consolide no espaço que lhe pertence e haja o pleno exercício de suas liberalidades e vocações, tão defesos pelo vasto ordenamento jurídico que a rege.

Apesar de ser mandamento defeso pela ordem constitucional e, valor reafirmado pelo Estatuto da Pessoa com Deficiência, não raro, nas tratativas estabelecidas entre a pessoa com deficiência e a instituição de ensino privada, não são e estão devidamente efetivados e operacionalizados os direitos fundamentais que compelem aos extraordinários pelos demais particulares. Nesse momento, caberá a busca pelo indivíduo extraordinário da otimização da aplicação do Princípio da Eficácia Horizontal dos Direitos Fundamentais. 
A horizontalização dos direitos fundamentais permite invocar a aplicação ou irradiação imediata das prerrogativas fundamentais, presentes no ordenamento jurídico constitucional brasileiro, a vínculos privados que sejam dotados de caráter público prestacional. O oferecimento da educação através do ensino particular bem ilustra o objeto material de uma relação privada, que tenha caráter público. ${ }^{13}$

Em uma sociedade democrática, pretende-se que reste estabelecido um vínculo equânime entre o aluno extraordinário e os particulares da educação, tendo em vista a operacionalização de direitos, públicos e privados, sob o viés eficaz horizontal e através da aplicação imediata da norma por parte de ambos os particulares que regem o liame estabelecido de âmbito educacional.

Desse modo, é necessária a alteração de paradigmas que desmistifiquem o condicionamento hipossuficiente da pessoa com deficiência dentro de um vínculo relacional privado, através da de fato aplicação da norma fundamental que tanto reclama pela inclusão escolar do indivíduo extraordinário. Em tendo sido desmistificado o indivíduo, desmistificado está a instituição social educacional da qual ele passa a pertencer.

\section{A INCLUSÃO ESCOLAR NA SOCIEDADE BRASILEIRA PRIVADA DE ENSINO}

A institucionalização da pessoa com deficiência em sociedade, e especialmente dentro de um vínculo particular de âmbito educacional, requer das pessoas que com ela se relacionem reconheçam nesse mesmo ente, um ser humano tão digno de ter efetuada suas prerrogativas quanto ele próprio o é dentro da relação que vier a existir entre os dois. A escola, por ser o primeiro ambiente socializador do homem, deve ser a primeira instituição social a que deve se requerer essa mesma institucionalização de maneira inclusiva.

Uma vez inserido na escola regular, qual ambiente substancial à formação Homem, a esse mesmo Homem lhe é propiciado o desenvolvimento de uma série de aptidões fundamentais, e o aprimoramento das já concebidas na primeira etapa do processo de

13 TEPEDINO, Gustavo. Apud: GONLÇAVES, Carlos Roberto. Direito Civil Brasileiro. 1.vol.14.ed.São Paulo: Saraiva, 2016. p.46. 
socialização - posturas e costumes assimilados ainda no seio familiar. Habilidades essas essenciais a eficaz socialização e integração em sociedade.

Segundo, o dispositivo do artigo 27 do Estatuto da Pessoa com Deficiência (Lei n. $\left.{ }^{\circ} 13.145 / 2015\right)$ :

Art. 27. A educação constitui direito da pessoa com deficiência, assegurados sistema educacional inclusivo em todos os níveis e aprendizado ao longo de toda a vida, de forma a alcançar o máximo desenvolvimento possível de seus talentos e habilidades físicas, sensoriais, intelectuais e sociais, segundo suas características, interesses e necessidades de aprendizagem.

Parágrafo único. É dever do Estado, da família, da comunidade escolar e da sociedade assegurar educação de qualidade à pessoa com deficiência, colocando-a a salvo de toda forma de violência, negligência e discriminação. ${ }^{14}$

A oportunidade de estar incluso na instituição de ensino regular, permite ao aluno com deficiência explorar um universo outrora limitado às suas insuficiências. Tanto a conquista do acesso ao conteúdo regular de ensino que consiste em aprender a ler; escrever e calcular; quanto através dos elos firmados do contato com os demais alunos - absortos de apresentarem qualquer deficiência, permite ao indivíduo extraordinário refletir e perceber mais concretamente o amplo espaço a sua volta, do qual deve participar como membro ativo. ${ }^{15}$

$\mathrm{O}$ acesso à educação, ferramenta essa propícia a igualar oportunidades em potencial, permitirá ao indivíduo extraordinário participar tão logo dos demais espaços sociais, dos quais a pessoa com deficiência se identifique e encontre autonomia para bem pertence-lo; da mesma maneira a qual é propiciada aos demais indivíduos. ${ }^{16}$

Ao ser proporcionado a sua participação como membro matriculado na rede regular de ensino, direito este fundamental e oponível a toda sociedade, sucede-se ao restabelecimento da outorga do pleno exercício da cidadania pela pessoa com deficiência. Visto que um dos principais compromissos da dinâmica educacional é com a formação de

\footnotetext{
${ }^{14}$ BRASIL, Estatuto da Pessoa com Deficiência (2015). In: CURIA, Luiz Roberto; CÉSPEDES, Lívia; ROCHA, Fabiana Dias da; colaboradores, op. cit., p. 1219-1231, nota 8.

${ }_{15}$ CURY, Carlos Roberto Jamil. DIREITO À EDUCAÇÃO: DIREITO À IGUALDADE, DIREITO À DIFERENÇA. São Paulo: Caderno de Pesquisa no 116, Julho de 2002. p.246. Disponível em: <http://www.scielo.br/scielo.php?script=sci_arttext\&pid=S0100-15742002000200010>. Acesso em 19.ago. 2018.

${ }^{16}$ Id., Ibid., nota 13.
} 
indivíduos hábeis a exercer e reclamar direitos, e de estarem comprometidos com seus deveres.

$\mathrm{E}$ aqui, pondere-se que os benefícios da inclusão escolar da pessoa com deficiência permitem o seguinte: Ao aluno com deficiência, frequentar a escola regular lhe propiciará o desenvolvimento de sua autonomia pessoal, somente passível de ser desenvolvida do contato de sua natureza individual com a natureza individual pertencente ao outro. Além da potencialização de sua capacidade de autoafirmação. ${ }^{17}$

Pois bem, um indivíduo é apto a posicionar-se racional e opinativamente dentro da sociedade reafirmando a autonomia que lhe é própria, a partir do momento em que empreende reflexões sobre a mesma sociedade e sobre o mesmo ambiente escolar privado. Posicionamento esse, que deriva do contato da pessoa com deficiência com os instrumentos do conteúdo básico de ensino ministrados nas salas de aula regular.

Aos demais alunos, reputados absortos de apresentarem qualquer manifestação de deficiência; o contato direto e diário dentro da sala de aula, com esses alunos ditos extraordinários, viabilizará que esses se tornem indivíduos mais solidários e mais solícitos a respeitarem o espaço e principalmente as limitações e restrições dos outros. ${ }^{18}$

Para que haja a verdadeira inclusão do aluno com deficiência, são necessários esforços que estão muito além do simples consentimento da instituição de ensino regular particular de matricular de tais alunos ${ }^{19}$, e aquém da propaganda inclusiva de muitas redes de ensino regular, que por vezes não atende como deveria o extraordinário da maneira que a norma exige eficazmente.

O que se espera da escola regular privada inclusiva, é nada além do que fornecimento de uma educação voltada para a realidade da sociedade brasileira atual, marcada pelo reconhecimento de dignidade à pessoa com deficiência e pela inegável conquista e efetivação de direitos, quer públicos e particulares.

Em linhas gerais, o que se espera da Instituição de ensino inclusiva é que esta, sendo reflexo da sociedade constituída, sirva de instrumento de transformação social dos parâmetros arcaicos e discriminadores; de objeto de desmarginalização e também de inclusão; de propósito para valorização da igualdade de condições e compreensão da

\footnotetext{
${ }^{17}$ DELLA TORRE, M.B.L. O Homem e a Sociedade: Uma Introdução à Sociologia. São Paulo-SP: Companhia Editora Nacional: 1985

18 PLETSCH, Márcia Denise. Repensando a inclusão escolar: diretrizes políticas, práticas curriculares e deficiência intelectual. Rio de Janeiro: Nau: Edur: 2010.p.65-83.

${ }^{19}$ PLETSCH, Márcia Denise, op. cit., nota 16.
} 
limitação de extraordinariedades; e principalmente de desígnio predisposto a amparar as demais trajetórias a serem percorridas pela pessoa com deficiência.

\section{A HORIZONTALIZAÇÃO DAS NORMAS FUNDAMENTAIS NA INSTITUIÇÃO DE ENSINO REGULAR PRIVADA: UMA REF̧LEXÃO SOBRE O JULGAMENTO DA ADI 5357}

O maior desafio da institucionalização e inclusão da pessoa com deficiência na escola regular privada é caracterizado pelo conflito em que a própria Instituição Escolar, quer seja essa de âmbito Privado, entrava consigo mesma. Vez que ainda é latente que muitas instituições privadas se encontrem resistentes a democratizar o oferecimento de ensino aos alunos extraordinários.

Representativo do impasse apresentado, caracterizado pela resistência, contrariedade e recusa de diversas instituições privadas abrirem suas portas para o ingresso, inclusão e permanência da comunidade de alunos extraordinários, a Confederação que as representa em todo o país, a CONAFEN, ${ }^{20}$ propôs perante o Supremo Tribunal Federal o julgamento da inconstitucionalidade de dispositivos normativos do Estatuto da Pessoa com Deficiência. ${ }^{21}$

Ao defender a pretensão pela escusa das escolas particulares de observarem as regras da Lei n. ${ }^{\circ} 13.146 / 2015$, a CONAFEN arguiu que tais instituições não deveriam ser compelidas de observar as normas que essencialmente caberiam somente ao Estado diligenciar. De adequação da instituição para recepção (obrigatória) dos alunos com deficiência que demonstrarem interesse em nela ingressar, sob os moldes do $\S 1^{\circ}$ do artigo

\footnotetext{
${ }^{20}$ A Confederação Nacional dos Estabelecimentos de Ensino é "a entidade máxima e única, em nível nacional, de representação da categoria, no caso, escolas particulares, em todos os seus graus." Disponível em: < https://www.confenen.org/>. Acesso em 19.ago.2018.

${ }^{21}$ O Julgamento da ADI 5357 pelo plenário do Supremo Tribunal Federal (STF) atestou a constitucionalidade das normas da Lei 13.146/2015 questionadas pela CONAFEN, na sessão do dia 09 de junho de 2016. Disponível em: http://www.stf.jus.br/portal/cms/verNoticiaDetalhe.asp?idConteudo=318570 $>. \quad$ Acesso
} em:19.ago.2018. 
28, e, sem a cobrança de qualquer taxa adicional na matrícula ou mensalidade, segundo o caput do artigo 30, do mesmo dispositivo legal. ${ }^{22}$ Por maioria de votos ${ }^{23}$, a Ação Direta de Inconstitucionalidade foi declarada improcedente pelo Plenário do Supremo Tribunal Federal. Da análise das razões de direito que fundamentaram os votos de cada ministro, um imperativo que sempre se faz constante preconiza o seguinte: para a interpretação e aplicação da norma infraconstitucional é imprescindível a análise dessa sob o crivo do que estabelece a norma constitucional. ${ }^{24}$

Desse modo, ao atestar a constitucionalidade, o plenário pretendeu pontuar o seguinte: não há como compreender ou mesmo colocar em exercício prático as normas, destinados à pessoa com deficiência, sem antes analisar os reflexos da eficácia dos preceitos fundamentais da Constituição Federal que incidem sobre esses mesmos dispositivos normativos, hierarquicamente abaixo, porém em harmonia com a ordem constitucional vigente ${ }^{25}$.

É inegável que o documento constitucional de 1988, outorgou inexorável valor a todas as pessoas indistintamente, o que incluiu a pessoa com deficiência. Ora, a construção de uma sociedade do amanhã que seja harmônica, livre, justa, igualitária, pluralista e sem preconceitos, como bem demarca o preâmbulo da Constituição, depende da apreciação desses valores universais e democráticos hoje.

Ou seja, é também inegável a necessidade que tais valores estejam entranhados, de maneira premente, já na etapa primeira do processo de ingresso em sociedade ou socialização da pessoa extraordinária, por meio de seu acesso irrestrito à educação oferecida pela rede regular de ensino de iniciativa privada.

\footnotetext{
${ }^{22}$ BRASIL, Supremo Tribunal Federal. 232 - Referendo na medida cautelar na ação direta de inconstitucionalidade 5.357 Distrito Federal. Requerente: Confederação Nacional dos Estabelecimentos de Ensino - CONAFEN. Relator: Ministro Edson Fachin. Brasília, p. 1-103, 09.jun.2016. Lex: Jurisprudência do STF. Disponível em: < http://redir.stf.jus.br/estfvisualizadorpub/jsp/consultarprocessoeletronico/ConsultarProcessoEletronic o.jsf?seqobjetoincidente $=4818214>$. Acesso em: 19.ago. 2018 .

${ }^{23}$ Ressalvada a ausência justificada do Ministro Celso de Melo, e o voto pela procedência parcial da ação pelo Ministro Marco Aurélio, por unanimidade de votos, a Sessão Plenária do STF julgou improcedente a ação direta de inconstitucionalidade 5357. Cf.: Id., Ibid., nota 20.

${ }^{24}$ Baseado nas razões de voto do Ministro Luiz Fux. In: BRASIL, Supremo Tribunal Federal, op. cit., p.37, nota 20 .

${ }^{25}$ Baseado nas razões de voto do Ministro Ricardo Lewandowski: In: Id., Ibid., p.100, nota 20.
} 
Pois é certo, que as escolas particulares, embora de iniciativa privada, exercem a prestação de um serviço público, sendo este tutelado pela norma constitucional em seu artigo $209^{26}$. O que implica dizer que, se o ensino inclusivo é mandamento defeso e política pública salvaguardada pela Constituição, certamente que, tal regra, deve ser observada também pela instituição privada, pois requerer a livre iniciativa da exploração da atividade prestacional da educação está condicionada ao cumprimento das normas gerais válidas indistintamente a toda e qualquer instituições de ensino do país.

$\mathrm{Na}$ apresentação das razões que fundamentaram o voto favorável a constitucionalidade da implementação do ensino inclusivo nas escolas particulares pelo Estatuto da Pessoa com Deficiência, asseverou o relator do julgamento no plenário, o Ministro Edson Fachin:

\begin{abstract}
[...]. Frise-se o ponto: o ensino privado não deve privar os estudantes - com e sem deficiência - da construção diária de uma sociedade inclusiva e acolhedora, transmudando-se em verdadeiro local de exclusão, ao arrepio da ordem constitucional vigente. [...] O ensino inclusivo é política pública estável, desenhada, amadurecida e depurada ao longo do tempo em espaços deliberativos nacionais e internacionais dos quais o Brasil faz parte. Não bastasse isso, foi incorporado à Constituição da República como regra. $^{27}$
\end{abstract}

Em verdade, a postura que muitas instituições privadas vinham adotando, anteriormente à entrada em vigor da Lei $n^{\circ}$. 13.146/2015, protelou o fenômeno da marginalização e exclusão das pessoas com deficiência, em decorrência de não aceitação do movimento inclusivo como parte integrante do ensino privado. Embora houvessem uma série de documentos normativos internacionais e nacionais - incluso as normas da Constituição Federal, que institucionalizaram a modalidade de ensino inclusivo como parte obrigatória e intrincada ao ensino regular.

Atendo-se a análise da inércia da escola privada em operacionalizar as normas de inclusão ao aluno com deficiência, depreende-se que por um longo período, tais instituições socializadoras estiveram aquém dos reflexos da horizontalização eficaz dos direitos

\footnotetext{
${ }^{26}$ Segundo a Constituição Federal, em seu art. 209. "O ensino é livre à iniciativa privada, atendidas as seguintes condições: I - cumprimento das normas gerais da educação nacional; II - autorização e avaliação de qualidade pelo Poder Público" In: BRASIL. Constituição (1988). Constituição da República Federativa do Brasil. In: CURIA, Luiz Roberto; CÉSPEDES, Lívia; ROCHA, Fabiana Dias da; colaboradores, op. cit., p.5-94, nota 8.

${ }^{27}$ Trecho das razões de voto do Ministro Relator Edson Fachin. In: BRASIL, Supremo Tribunal Federal, op. cit., p.20, nota 20.
} 
fundamentais da Carta Magna de 1988. E, por muito tempo enalteceram valores outros ao "arrepio da ordem constitucional vigente", que arbitraram a maneira de estabelecer vínculos com os alunos que se interessariam em ingressar na instituição, e, que de sobremaneira impediram a admissão do aluno extraordinário.

Doravante sob o arrepio da norma constitucional, na hipótese de a norma pública cogente deixar de ser instrumentalizada pelo não exercício prático do estipulado pela norma particular, prevista no Estatuto da Pessoa com Deficiência - responsável por regulamentar as singularidades de cada relação que se estabelece em sociedade pela pessoa com deficiência, e, neste âmbito, a relação aluno com deficiência com escola particular -, coíbe-se o fenômeno da irradiação dos direitos fundamentais sobre essa relação privada.

Ao contrário, se escola regular privada estiver adepta aos reflexos da horizontalização dos direitos fundamentais, e principalmente, adepta a enquadrar-se aos parâmetros de escola inclusiva, a escola privada se propõe a enxergar na pessoa com deficiência, que se interessa em ingressar em seus estabelecimentos, ser esta qual sujeito extraordinário digno de ter seus direitos efetuados, pelo simples fato de ser indivíduo titular da norma irradiante, como qualquer outro. $\mathrm{O}$ que sinalizaria o enfim rompimento com o estigma da relação arbitrária e marginalizadora.

Apesar do paradigma da socialização do aluno extraordinário na escola ainda gerar controvérsia, ${ }^{28}$ do julgamento de constitucionalidade e entrada em vigor da Lei $n^{\circ}$. 13.146/2015 é incontroverso o dever de seu cumprimento imediato pelos estabelecimentos de ensino privado. Desse modo, a relação estabelecida entre os particulares da educação e os particulares extraordinários resta subordinada ao cumprimento do que está legalmente previsto e mandamentamente defeso: a execução irrestrita dos direitos pessoa com deficiência pelas vias de sua inclusão na instituição de ensino regular privada.

\section{CONSIDERAÇÕES FINAIS}

\footnotetext{
28“Quando se mudam as perspectivas analíticas de um tema em função das mudanças paradigmáticas leva tempo até as novas compreensões alcançarem as práticas cotidianas.” In: SANTOS, Wederson. Deficiência como restrição de participação social: desafios para avaliação a partir da Lei Brasileira de Inclusão. Disponível em: <http://www.scielo.br/pdf/csc/v21n10/1413-8123-csc-21-103007.pdf $>$. Acesso em: 19.ago.2018. p. 2.
} 
A trajetória da pessoa com deficiência para a conquista a efetivação dos seus direitos encontrou muitos obstáculos dos quais necessitaram serem sobrelevados, através do empenho conjunto da Sociedade e do Estado, outrora instituições marginalizadoras do indivíduo extraordinário.

Ao ser apresentado a necessidade de aplicação dos direitos fundamentais nas relações horizontais, estabelecidas entre a escola regular privada e o aluno com deficiência, visa-se tornar permanente, também na política institucional particular, a democratização do ensino, através da inclusão do extraordinário em seus ambientes.

Embora haja uma série de dispositivos regulamentadores dos direitos da pessoa com deficiência, aqui sinteticamente apresentados e derivados da Constituição Federal de 1988 e do Estatuto da Pessoa com Deficiência, é possível ainda ser verificado certa resistência por parte da instituição de ensino privada, no que diz respeito a operacionalizar as prerrogativas fundamentais presentes em tais documentos. Como bem demonstrou a análise centrada no julgamento da ADI 5357.

Contudo, da análise da repercussão que tomou o julgamento, ilustrado pelo voto de cada ministro que julgou pela constitucionalidade da Lei $n^{\circ} .13 .146 / 2015$, constata-se ser possível vislumbrar uma sociedade porvir, e que já está em fase de maturação, que tenha enfim superado seu caráter segregacionista, recriminatório e imparcial de seus institutos, especialmente de cunho educacional.

Uma sociedade educacional que valorize a figura do extraordinário como semelhante seu, que tenha compreendido a partir do contato em sala de aula, primeiro espaço socializador, a fundamental importância de se posicionar como membro solidário e fraterno. E, que tenha aprendido ainda, que a chave para a construção de um ambiente inclusivo e harmônico depende tão somente do respeito do espaço e das limitações do outro, e que principalmente, depende da valorização das extraordinariedades compartilhadas por cada ser humano.

\section{REFERÊNCIAS BIBLIOGRÁFICAS}

ARAÚJO, Luiz Alberto David; NUNES JÚNIOR, Vidal Serrano. Curso de Direito Constitucional. 14.ed. São Paulo Saraiva, 2010 
BOLONHINI JUNIOR, Roberto. Portadores de necessidades especiais: as principais prerrogativas e a legislação brasileira. São Paulo: Arx, 2004.

BRASIL, CONAFEN. Confederação Nacional dos Estabelecimentos de Ensino. Disponível em: < https://www.confenen.org/>. Acesso em 19.ago.2018.

BRASIL. Constituição (1988). Constituição da República Federativa do Brasil. In: CURIA, Luiz Roberto; CÉSPEDES, Lívia; ROCHA, Fabiana Dias da; colaboradores. Vade Mecum. São Paulo: Saraiva 2016. p.5-94.

BRASIL, Estatuto da Pessoa com Deficiência (2015). In: CURIA, Luiz Roberto; CÉSPEDES, Lívia; ROCHA, Fabiana Dias da; colaboradores. Vade Mecum. São Paulo: Saraiva 2016.p. 1219-1231.

BRASIL, STF notícias. Escolas particulares devem cumprir obrigações do Estatuto da Pessoa com Deficiência, decide STF. Disponível em: < http://www.stf.jus.br/portal/cms/verNoticiaDetalhe.asp?idConteudo=318570 >. Acesso em:19.ago.2018.

BRASIL, Supremo Tribunal Federal. 232 - Referendo na medida cautelar na ação direta de inconstitucionalidade 5.357 Distrito Federal. Requerente: Confederação Nacional dos Estabelecimentos de Ensino - CONAFEN. Relator: Ministro Edson Fachin. Brasília, p. 1-103, 09.jun.2016. Lex: Jurisprudência do STF. Disponível em: <

http://redir.stf.jus.br/estfvisualizadorpub/jsp/consultarprocessoeletronico/ConsultarProcessoEletronic o.jsf? seqobjetoincidente $=4818214>$. Acesso em: 19.ago.2018.

CASTILHO, Ricardo. Direitos Humanos. 3.vol. São Paulo: Saraiva, 2011

CURIA, Luiz Roberto; CÉSPEDES, Lívia; ROCHA, Fabiana Dias da; colaboradores. Vade Mecum. São Paulo: Saraiva 2016.

CURY, Carlos Roberto Jamil. DIREITO À EDUCAÇÃO: DIREITO À IGUALDADE, DIREITO À DIFERENÇA. São Paulo: Caderno de Pesquisa no 116, Julho de 2002. p.246. Disponível em: $<$ http://www.scielo.br/scielo.php?script=sci_arttext\&pid=S0100-15742002000200010〉. Acesso em 19.ago. 2018

DELLA TORRE, M.B.L. O Homem e a Sociedade: Uma Introdução à Sociologia. São Paulo-SP: Companhia Editora Nacional: 1985

MANTOAN, Maria Teresa Eglér; PIETRO, Rosângela Gavioli; Valéria Amorim Arantes organizadora. Inclusão escolar: pontos e contrapontos. 5.ed. São Paulo: Summus, 2006.

PLETSCH, Márcia Denise. Repensando a inclusão escolar: diretrizes políticas, práticas curriculares e deficiência intelectual. Rio de Janeiro: Nau: Edur: 2010.p.65-83.

ROCHA, Cármen Lúcia Antunes, ROCHA, Cármen Lúcia Antunes. O princípio da dignidade da pessoa humana e a exclusão social. Disponível em: < http://egov.ufsc.br/portal/sites/default/files/anexos/32229-38415-1-PB.pdf>. Acesso em: 07.fev.2018. 
SANTOS, Wederson. Deficiência como restrição de participação social: desafios para avaliação a partir da Lei Brasileira de Inclusão. Disponível em: <http://www.scielo.br/pdf/csc/v21n10/14138123-csc-21-10-3007.pdf>. Acesso em: 19.ago.2018. p. 2.

SARMENTO, Daniel. Direitos Fundamentais e Relações Privadas. Rio de Janeiro: Lúmen Juris Editora, 2004

SOUZA, Tânia Mara Pinto de. Da Tutela Dos Direitos difusos e coletivos das Pessoas com Deficiência: uma breve abordagem. In: CARVALHO, Marco Cesar (ORG.) CIA, Michele (ORG.). Apresentação de Henrique Gaberllini Carnio. Direitos Fundamentais: história, evolução e problemas atuais. 1.ed. Passos- MG: Gráfica e Editora São Paulo, 2015. p., p. 355-356.

TEPEDINO, Gustavo. Apud: GONLÇAVES, Carlos Roberto. Direito Civil Brasileiro. 1.vol.14.ed.São Paulo: Saraiva, 2016. p.46.

TISESCU, Alessandra Devuksky da Silva; SANTOS, Jackson Passos. Apontamentos históricos sobre as fases de construção dos direitos humanos da pessoa com deficiência. Disponível em: < www.publicadireito.com.br/artigos/?cod=24f984f75f37a519>.Acesso em:19.ago. 2018. 